\title{
Flatness optimisation of micro-injection moulded parts: the case of a PMMA microfluidic component
}

\author{
S Marson ${ }^{1}$, U M Attia ${ }^{1}$, G Lucchetta ${ }^{2}$, A Wilson ${ }^{3}, J_{\text {R Alcock }}{ }^{1}$ and D M Allen ${ }^{1}$ \\ ${ }^{1}$ Cranfield University, Cranfield, Bedfordshire, MK43 0AL \\ ${ }^{2}$ DIMEG, University of Padova, Padova, Italy \\ ${ }^{3}$ National Physical Laboratory, Teddington, Middlesex, TW11 0LW \\ E-mail: s.marson@cranfield.ac.uk, Fax +44 (0)1234 751346
}

\begin{abstract}
Micro-injection moulding ( $\mu$-IM) has attracted a lot of interest because of its potential for the production of low-cost, miniaturised parts in high-volume. Applications of this technology are, amongst others, microfluidic components for lab-on-a-chip devices and micro-optical components. In both cases the control of the part flatness is a key aspect to maintaining the component's functionality.
\end{abstract}

\begin{abstract}
The objective of this work is to determine the factors affecting the flatness of a polymer part manufactured by $\mu$-IM and to control the manufacturing process with the aim of minimising the in-process part deformation. As a case study a PMMA microfluidic substrate with overall dimensions of $10 \mathrm{~mm}$ diameter and $1 \mathrm{~mm}$ thickness was investigated by designing a $\mu$-IM experiment having flatness as the experimental response. The part flatness was measured using a micro-coordinate measuring machine. Finite elements analysis was also carried out to study the optimal ejection pin configuration.
\end{abstract}

The results of this work show that the control of the $\mu$-IM process conditions can improve the flatness of the polymer part up to about $15 \mu \mathrm{m}$. Part flatness as low as $4 \mu \mathrm{m}$ can be achieved by modifying the design of the ejection system according to suggested guidelines.

\section{Introduction}

Micro-injection moulding ( $\mu$-IM) is a microreplication technique that offers mass-production capabilities for polymer parts at relatively low cost, short-cycle times (a few seconds), fullautomation, accurate replication and good dimensional control [1]. Hence, micro-injection moulding is currently used commercially for the production of a number of biomedical miniaturised devices and miniaturised optical components for consumers' products by companies, such as Micralyne, Abbott and Microfludic ChipShop.

Similar to conventional Injection Moulding, $\mu$-IM is a technology in which a thermoplastic material is fed in the form of granules into the plasticating unit and then injected at high pressure into a mould, which is the inverse of the desired shape. The molten polymer freezes into the mould cavity which contains features of micrometre $(\mu \mathrm{m})$ or nanometre $(\mathrm{nm})$ dimensions which need to be completely filled by the polymer melt - becoming a solid part and is then released from the mould by opening the mould and ejecting the plastic part with a set of ejection pins. The whole process is normally very fast with production cycles of a few seconds.

The dimensional integrity of the as-moulded parts is determined by the thermal history of the polymer within the mould cavity, by the ejection process and by the rapid cooling of the part to room temperature following ejection from the mould [2]. Design-of-Experiments (DOE) approaches have 
been extensively used with the aim of identifying the $\mu$-IM influential process parameters on the part quality, in particular looking at responses related to the filling quality of small cavities [3-7].

Amongst the numerous products manufactured by $\mu$-IM are microfluidic devices for biotechnology, ink-jet printing and analytical chemistry applications and micro-optical components.

One of the main issues related to the fabrication of working polymer microfluidic devices is the sealing of the device with a lid or capping layer to provide an enclosed microfluidic path. This step is always necessary to ensure the device functionality. A number of techniques including both direct bonding such as thermal fusion bonding, solvent bonding or ultrasonic welding and indirect bonding such as adhesive bonding were attempted to seal thermoplastic microfluidic devices [8]. A common issue raised by many experts in the field is the requirement for the mating parts to be flat to minimise the processing pressure or the temperature which could otherwise result in stressed parts or deformation of parts/channels $[8,9]$ or for the micro-assembly of microfluidic devices [10]. Despite flatness is being identified as common prerequisite, very little information is available on the required and achievable flatness of thermoplastic miniaturized components for microfluidic devices. Goretty and Adams [11] achieved replication of micron-size features in $300 \mathrm{~mm}$ plastic wafers that exhibited flatness of better than $100 \mu \mathrm{m}$ edge to edge along the wafer diameters.

Injection-moulding (and its variant compression-injection moulding) is an established technology for the manufacture of diffractive optical elements on stable thick substrates $(>1 \mathrm{~mm})$ with shallow features on the micron scale (such as found in CDs and DVDs) [12]. However, it is difficult to fabricate thin substrates and very small patterns with high aspect ratios [13]. $\mu$-IM is a technology suitable for the manufacture of polymer micro-optics such as micro lens arrays or Fresnel lenslets with micro-features having an aspect ratio higher than 1:1. The control of the diffractive optical elements deformation is critical to ensure the component's correct functionality. As the size of the optic decreases, tolerances on parameters such as the radius of the lens, the outer diameter and the focal length become very tight [14]. Deformations of the polymer substrate (radial tilt) could deteriorate the form accuracy of the replicated optical component causing aberrations and thus loss of the image quality.

This paper concerns the optimisation of the flatness of miniaturised polymer parts manufactured by $\mu$-IM where flatness is here defined as the distance between the two parallel planes which include the polymer part top face (figure 1) $[15,16]$.



Figure 1. Schematic representation of the polymer part flatness 
As a case study, a microfluidic PMMA component for application in biomedical lab-on-a-chip devices was investigated. The control of the microfluidic part flatness was addressed in two different ways:

- by controlling the manufacturing chain via optimisation of the $\mu$-IM process using a DOE approach

- by evaluating possible ejection system design alternatives and their effects on the part deformation using FE analysis.

In addition, with the aim of evaluating the effect of different mould surface finish on the part deformation, the same micromould was manufactured using two different metal cutting techniques: micromilling and diamond turning and the flatness of the corresponding polymer parts were measured and compared.

\section{Experimental}

\subsection{Polymer component manufacture}

The microfluidic device under investigation is a plasma separator for the preparation of blood samples. The device comprises a set of poly-(methylmethacrylate) (PMMA) discs (Altuglas, VSUVT) which are assembled together by a lamination process (figure 2). Details on the device functionality and on the manufacturing route are available in a previous publication [17].



Figure 2. (A) Set of PMMA polymer discs, (B) device assembly, (C) device cross section and (D) 3D microfluidic path within the assembled device.

Of the five discs comprising the device, one in particular was the subject of this study (figure $3 \mathrm{~b}$ ). The nominal dimensions of the disc were $1 \mathrm{~mm}$ thickness and $10 \mathrm{~mm}$ diameter. 

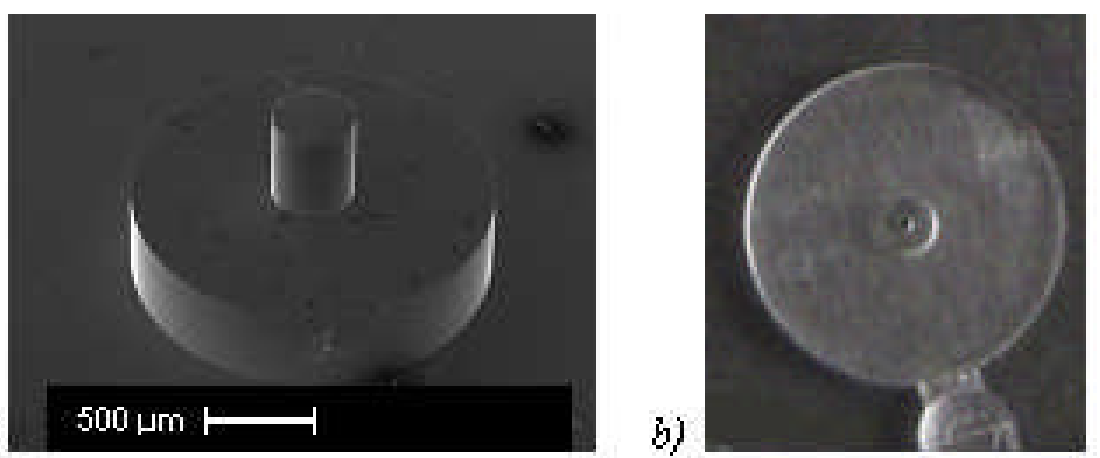

Figure 3. Geometry of the disc subject of this study a) Detail of the central feature of the micromould and b) resulting polymer part. The through-hole produced by replication of the mould appears at the centre of the polymer disc in figure $3 \mathrm{~b}$.

The five PMMA polymer discs comprising the device of figure 2 were manufactured using a Microsystem-50, Battenfeld in one shot and then separated from the sprue in a separate stage of the process. The fixed moulding process conditions were: melt temperature $250^{\circ} \mathrm{C}$, mould temperature $84^{\circ} \mathrm{C}$, injection speed $200 \mathrm{~mm} / \mathrm{s}$ and packing pressure $400 \mathrm{bar}$. These parameters were optimised in a separate experiment with the aim of obtaining a set of compromise parameters, which would result in high filling quality for the considered disc when producing all five discs in a single mould by one shot [3].

The parameters of ejection pin velocity, ejection pin force and cooling time were considered to play a major role in the parts deformation and were considered as process variables and changed according to the two levels, full factorial DOE indicated in table 1.

Table 1. DOE table indicating the high and low levels of three process variables (ejection pin velocity, ejection pin force, cooling time).

\begin{tabular}{c|ccc}
\hline Run & $\begin{array}{c}\text { Ejection pin velocity } \\
(\mathrm{mm} / \mathrm{s})\end{array}$ & $\begin{array}{c}\text { Ejection pin force } \\
(\mathrm{kN})\end{array}$ & $\begin{array}{c}\text { Cooling } \\
\text { time } \\
(\mathrm{s})\end{array}$ \\
\hline 1 & 150 & 0.8 & 8 \\
2 & 300 & 0.8 & 4 \\
3 & 150 & 0.4 & 4 \\
4 & 300 & 0.4 & 8 \\
5 & 300 & 0.8 & 8 \\
6 & 150 & 0.8 & 4 \\
7 & 300 & 0.4 & 4 \\
8 & 150 & 0.4 & 8 \\
\hline
\end{tabular}




\subsection{Flatness measurements}

Both polymer discs and metal micromould were measured using a Zeiss F25 Coordinate Measurement Machine (CMM), which is designed for the measurement of size, form and position of micro parts. The CMM machine has a $300 \mu \mathrm{m}$ diameter tactile scanning probe and a visual inspection system that can be used in conjunction with the tactile probe. The probing force was always lower than $0.5 \mathrm{mN}$.

The measuring strategy for the polymer discs was as follows:

1. For each experimental run indicated in table 1 a sample of three parts was selected from a batch of approximately twenty parts. The polymer discs were detached from the sprue, cleaned and located on a ceramic reference platen (flatness $<50 \mathrm{~nm}$ ) held using double-sided carbon tape (figure 4).

2. The platen and disc were positioned in the micro-CMM

3. The platen was probed around the polymer disc to generate the $\mathrm{z}$ datum plane

4. The disc was probed in a point pattern of concentric circles ranging from 6 to $9 \mathrm{~mm}$ in diameter

5. Flatness data were collected. Three measurements of the top surface were taken on each part for a total of nine measurements.

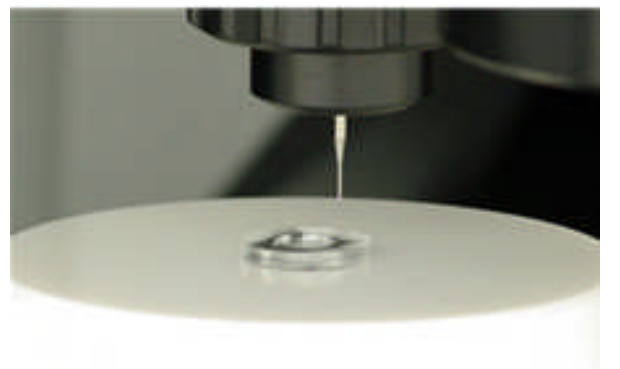

Figure 4. Polymer disc positioned onto the ceramic reference platen of the Zeiss CMM machine. The image shows also the tactile scanning probe.

\subsection{Finite Element analysis}

A preliminary numerical simulation of the injection moulding process was conducted using Autodesk Moldflow Insight 2010 to predict the process-induced warpage and the temperature distribution within the polymer disc prior to ejection. To improve the results accuracy the material used was characterised both rheologically and thermally. Structural finite element simulations were then carried out using Ansys 11 to analyse the deformation of the polymer disc with a 2, 3 and 4ejection pins configuration. In all cases the pins were positioned at $1 \mathrm{~mm}$ from the disc edges in a symmetric configuration (180, 120 and $90^{\circ}$ respectively). The mechanical properties of PMMA used in the FEA simulation were based on data available from the literature [18] and from measurements of the storage modulus performed by Dynamic Mechanical Thermal Spectrometry. The mechanical behaviour of PMMA was modelled as bilinear elasto-plastic with isotropic hardening and with properties that change with temperature. This model was chosen because it can satisfactorily approximate the PMMA mechanical behaviour for very small plastic deformations. The values used in the simulations are listed in table 2. 
Table 2. Mechanical properties of PMMA

\begin{tabular}{c|cccc}
\hline $\begin{array}{c}\text { Temperature } \\
\left({ }^{\circ} \mathrm{C}\right)\end{array}$ & $\begin{array}{c}\text { Young's } \\
\text { Modulus E } \\
(\mathrm{MPa})\end{array}$ & $\begin{array}{c}\text { Yield strength } \\
(\mathrm{MPa})\end{array}$ & $\begin{array}{c}\text { Hardening slope } \\
(\mathrm{MPa})\end{array}$ & Poisson ratio \\
\hline 80 & 1200 & 40 & 800 & 0.35 \\
92 & 702 & 28 & 468 & 0.35 \\
110 & 18.6 & 5 & 12.4 & 0.35 \\
126 & 3.7 & 1 & 2.5 & 0.35 \\
144 & 2.4 & 0.4 & 1.2 & 0.35 \\
\hline
\end{tabular}

The PMMA friction coefficient was estimated to be 0.6 [19] and the part shrinkage on the central mould core (stepped cylinder) was calculated from the process simulation.

As the whole system is symmetric, only half of the polymer disc was simulated in the 2 and 4-pins configurations and the disc as a whole was simulated for the 3-pins configuration. The meshes around the central cavity and around the two circular areas where the ejector pins contact the disc were refined to have uniform pin loading and friction force distributions. Figure 5 shows the FE mesh for a two-pin ejection system.

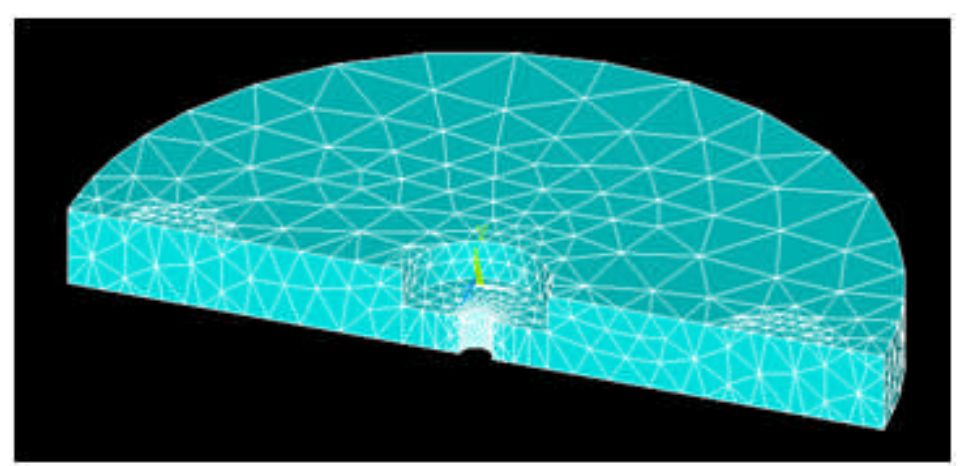

Figure 5. FE Mesh for the two-pin ejection system

The contact pressure between the central mould core and the polymer disc were calculated following the procedures reported in [20] and [21]. The friction force $f$ on each cylindrical step is proportional to the contact pressure $\mathrm{P}$ (equation 1 ):

$$
f=\mu \cdot P \cdot(2 \pi \cdot r \cdot L)
$$

where $\mu$ is the coefficient of friction, $r$ is the radius of the cylinder and $L$ is the height of the cylinder.

Since the value of contact pressure significantly depends on the polymer modulus of elasticity, which in turn varies with temperature across the polymer thickness, the friction force on the central mould core was calculated integrating the contact pressure across the thickness. The values used in the simulations are listed in table 3 as a function of the cooling time. 
Table 3. Friction force between the central mould core and the polymer disc for different cooling times

\begin{tabular}{c|ccc}
\hline Cooling time (s) & 4 & 8 & 12 \\
\hline Friction force (N) & 3.8 & 9.5 & 10.0 \\
\hline
\end{tabular}

\section{Results and discussion}

\subsection{Micro-injection moulding process control}

Figure 6 shows the flatness plot of a typical micro-injection moulded polymer disc with flatness around the $50 \mu \mathrm{m}$ level. The rectangle situated in proximity of corner 3 of the plot indicates the position of the gate in the polymer disc that in all cases corresponded to the lowest point in the plot. All discs were formed into saddle-shaped, biconvex surfaces.

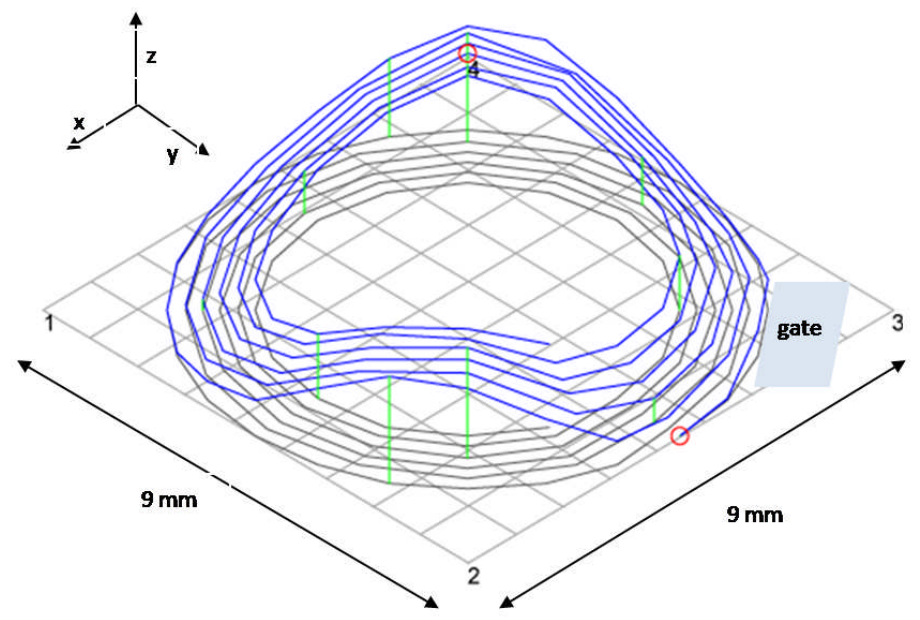

Figure 6. Flatness plot of a typical micro-injection moulded polymer disc with flatness around the $50 \mu \mathrm{m}$ level. The shape of the plot was representative of all discs.

The measured parts flatness for each experimental run (table 1) is reported in table 4. The calculated standard deviation was always very small confirming that the measurements are very repeatable thus giving confidence that the experimental set-up did not introduce errors in the measurement.

Table 4. Table indicating the measured flatness of the manufactured parts for each of the experimental runs of table 1 . The reported values are the average over 9 measurements with their standard deviations.

\begin{tabular}{l|cccccccc}
\hline Run & 1 & 2 & 3 & 4 & 5 & 6 & 7 & 8 \\
& & & & & & & & \\
\hline Flatness & 46.24 & 89.71 & 99.62 & 46.08 & 44.57 & 101.37 & 98.44 & 46.53 \\
$(\mu \mathrm{m})$ & \pm & \pm & \pm & \pm & \pm & \pm & \pm & \pm \\
& 0.07 & 0.16 & 0.19 & 0.04 & 0.04 & 0.22 & 0.46 & 0.01 \\
\hline
\end{tabular}

The saddle shape of the polymer discs and the position of the highest points relative to the gate suggest that the deformation is caused by the impact of the ejection pins on the part during the 
demoulding process (figure 7). We will call this type of deformation from hereafter ejection warpage. Other possible sources of warpage such as (i) non-uniform mould temperature between the mould two-halves or (ii) polymer flow-induced anisotropy of the thermal expansion coefficient were excluded as possible major sources of the observed deformation, because of the observed biconvex shape of the deformed parts. A thermal gradient between the mould two-halves (case i) would result in one side of the component to cool down more rapidly causing a thermal stress that is then relieved when the mould opens. In the case of symmetric geometries like the one considered here, a fully symmetric part warpage (bowed shape) would be expected. A non-uniformity caused by a flowinduced gradient of the thermal expansion coefficient (case ii) would result in parts that are only deformed along their diameter and not in their thickness. This phenomenon would result in an ovalshaped part.

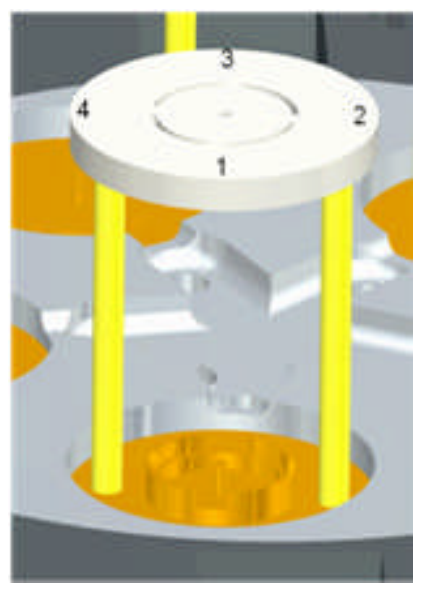

Figure 7. Ejection system hitting the polymer part during the demoulding process. The numbers (1 to 4) in the picture refer to the positions indicated in the flatness plot of figure 6 .

Another possible source of deformation of the polymer parts could be the flatness of the micromould itself. With the aim of excluding this factor the mould flatness was also measured. This was found to be in the order of $1 \mu \mathrm{m}$. Therefore it was possible to conclude that the mould flatness was not significantly affecting the geometry of the polymer parts.

The influence of the $\mu$-IM process parameters listed in table 1 on the part flatness was evaluated using the main-effects plot. A main-effect plot for a particular factor is a plot of the average of the data points at the low factor setting and the average of the data points at the high factor setting. The larger the slope of the line that connects the two averages, the more important the effect is. Figure 8 shows that the only statistically significant parameter affecting the part flatness is the cooling time. The slope of the plot indicates that the flatness decreases with increased cooling time. 


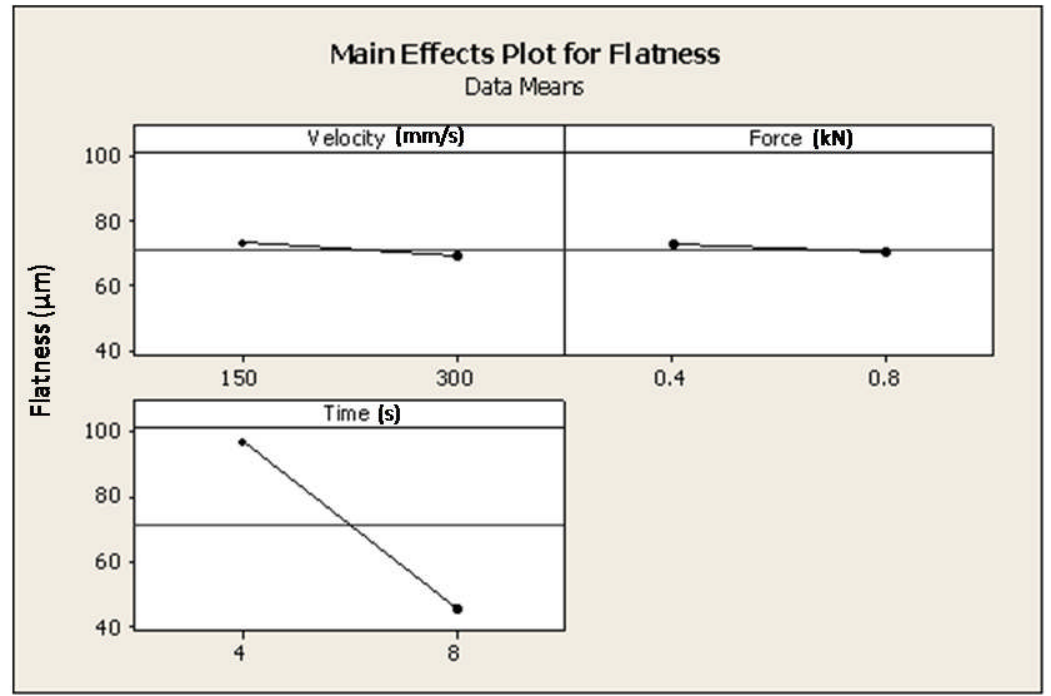

Figure 8. Main-effects plot for the parts flatness.

Based on the interpretation of the main effects plot, the parts were moulded with increased cooling time $(4-40 \mathrm{sec})$ with the aim of reducing the part deformation therefore improving the flatness.

The graph in figure 9 represents the trend of the measured parts flatness vs. cooling time. The measurement uncertainty quoted in legend $(0.25 \mu \mathrm{m})$ is the measurement uncertainty of the microCMM machine. Any error associated with length dependent terms is small compared to this and therefore was neglected. Figure 9 shows that the plastic deformation decreases with the increased cooling time reaching a plateau at approximately $15 \mu \mathrm{m}$. The presence of a plateau suggests that it is not possible to increase indefinitely the cooling time to obtain parts with flatness lower than $15 \mu \mathrm{m}$. This would also be impractical in industrial settings as it would considerably increase the production cycle-time.

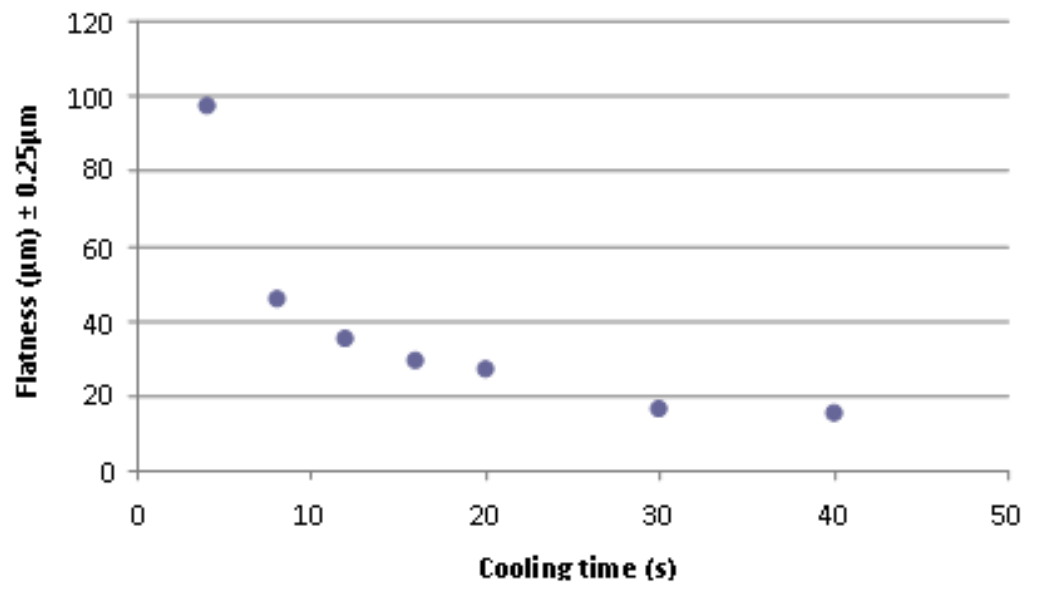

Figure 9. Measured polymer parts flatness vs. cooling time. 


\subsection{Ejection forces control}

Polymer parts were manufactured using a micromould machined with two different metal cutting techniques: micromilling and diamond turning and the flatness of the corresponding polymer parts were measured. The Ra values for the two micromoulds and the corresponding flatness of the polymer parts are reported in table 5.

Table 5. Comparison of micromould surface finish and resulting flatness of the polymer parts using micromilling and diamond turning as the mould manufacturing techniques. The polymer parts roughness is also reported.

\begin{tabular}{c|cc}
\hline & \multicolumn{2}{|c}{ Micromould Manufacturing technique } \\
\cline { 2 - 3 } & Micromilling & Diamond turning \\
\cline { 2 - 3 } Micromould surface roughness Ra $(\mathrm{nm})$ & 90 & 3 \\
Polymer parts Flatness $(\mu \mathrm{m})$ & $13.9 \pm 2.7$ & $13.7 \pm 1.2$ \\
Polymer parts roughness $\mathrm{Ra}(\mu \mathrm{m})$ & $0.26 \pm 0.10$ & $0.12 \pm 0.06$ \\
\hline
\end{tabular}

It can be noted from the values reported in table 5 that despite diamond turning provides a surface finish that is at least one order of magnitude better than micromilling, the resulting polymer parts flatness is not significantly affected.

During the ejection process the friction forces, which are responsible for the ejection warpage, develop between the polymer and the surface of the mould. The coefficient of friction was observed to increase with the roughness as a result of the mechanical behaviour of the surface topography on the polymer exhibiting a minimum for $\mathrm{Rt}=2 \mu \mathrm{m}$ [19]. For highly polished surfaces $(\mathrm{Rt}<2 \mu \mathrm{m})$ the coefficient of friction was observed to increase because of the significant effect of adhesion forces between surfaces. It is possible that for the two different reasons mentioned above the coefficient of friction is not at its minimum in both the cases reported in table 5. A minimum might be obtainable for surface finish $3<\operatorname{Ra}<90 \mathrm{~nm}$.

\subsection{Simulations}

The predicted disc process-induced warpage is shown in figure 10, where deflection results are plotted anchoring the centre of the disc to the XY plane, so that they can be directly compared to the flatness measurements. The calculated flatness is around $5 \mu \mathrm{m}$ regardless of the cooling time. 


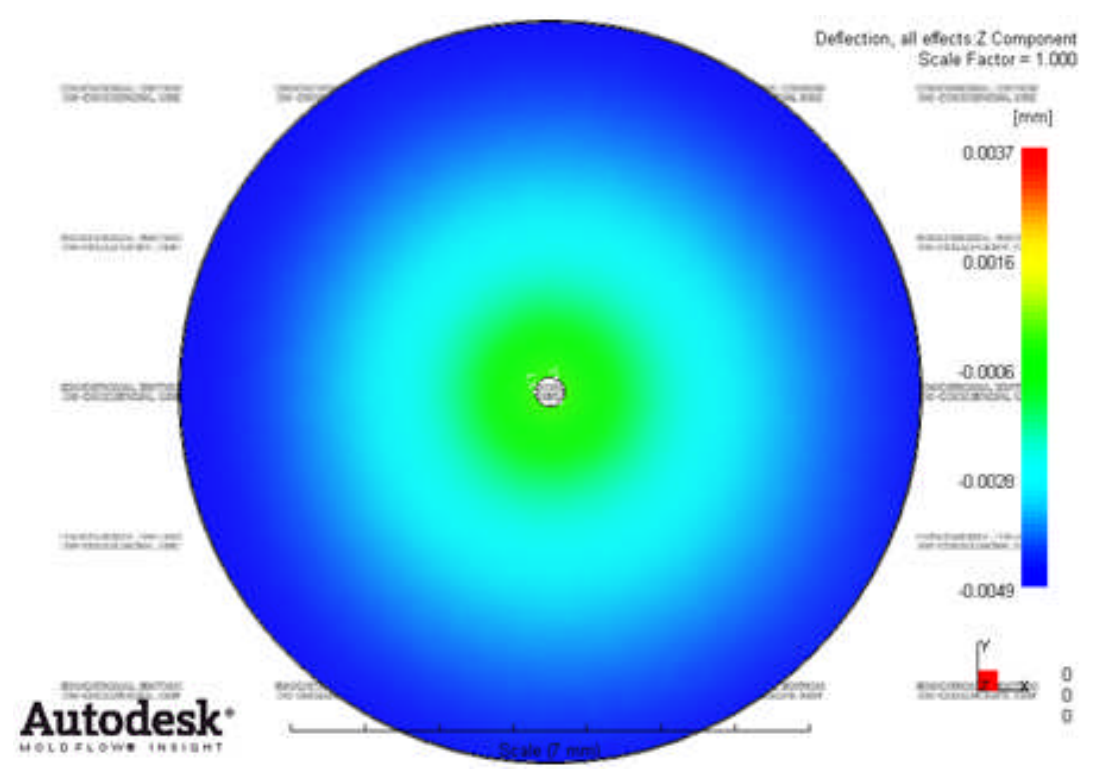

Figure 10. Predicted disc process-induced warpage

The analyses revealed that the deformation is mainly caused by the differential shrinkage between the top (larger diameter hole) and the bottom side of the disc. This is due to fact that the gate is located nearer to the side containing the smaller diameter central pin. The warpage induced by the thermal effects and the molecular orientation was negligible. It is also interesting to notice that the ejection warpage is expected on the direction opposite to the process warpage therefore counteracting this effect.

As the disc material properties vary with temperature, cooling simulations were conducted to obtain the temperature distribution in the polymer disc at the moment of ejection. The results are shown in figure 11 as a function of the cooling time. Since the part is ejected immediately after the mould opens, the heat loss through the bottom side by natural convection was neglected.

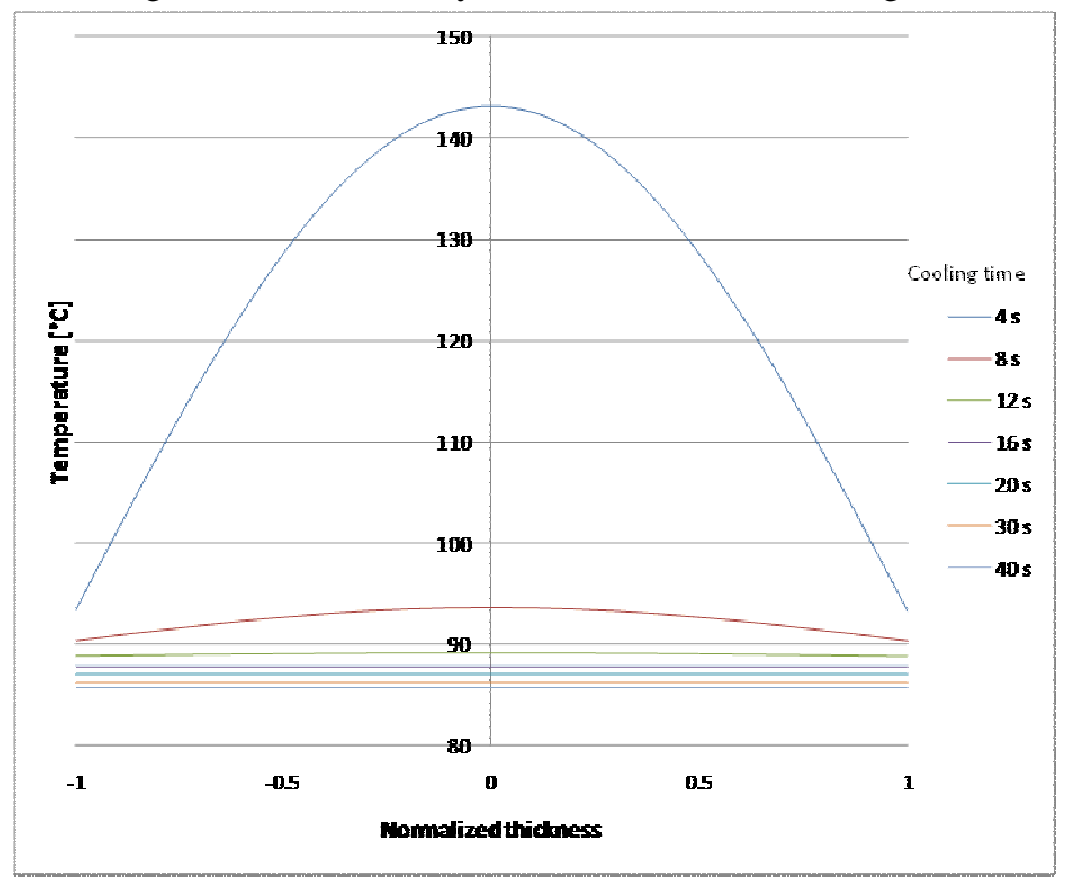

Figure 11. Temperature distribution on the polymer disk prior to ejection, as calculated at a reference point located at $5 \mathrm{~mm}$ from the disc centre. 
For short cooling times $(\sim 4 \mathrm{~s})$ the part temperature largely varies ranging from $93^{\circ} \mathrm{C}$ at the cavity surface up to $143^{\circ} \mathrm{C}$ at the core, passing the glass transition temperature $\left(\mathrm{T}_{\mathrm{g}}\right)$ that, for this polymer grade, is around $102^{\circ} \mathrm{C}$. It is important to note that near to the $\mathrm{T}_{\mathrm{g}}$ the material behaviour - especially the elastic modulus - is highly sensitive to changes in temperature [18]. This behaviour can explain the trend in the ejection warpage observed in figure 9. For short cooling times, at the moment of ejection, the core of the part is still at a temperature higher than $T_{g}$, therefore the elastic modulus is considerably lower than the one of the skin layer. The longer the cooling time the lower the temperature averaged across the thickness and, therefore, the stiffer the part.

\subsection{Ejection system modification}

The effect of a different configuration of the ejection system (2,3 and 4 ejection pins) on the ejection warpage was studied using FE simulation. The first step was to study the ejection warpage of the micro polymer disc caused by the 2-pins ejection process. Subsequently the developed model was used to determine the ejection warpage using a 3-and 4-pins ejection system.

In the FE structural analysis, the two concentric holes were constrained along the disc axial direction with zero displacement. The calculated frictional force was applied to the two circular areas where the two $1 \mathrm{~mm}$ diameter ejection pins contact the disc during the ejection process, with a resulting pressure of $2.45 \mathrm{~N} / \mathrm{mm}^{2}$ for a cooling time of $4 \mathrm{~s}$. To differentiate between plastic and elastic deformation, the static loads from the pins are applied in time steps, uploading up to the full load value then downloading to zero load. The results from this approach show that a significant part of the deformation is elastic, which recovers when load is removed whilst the remaining plastic deformation is only a small fraction of the overall disc deflection.

The displacement plots in the $\mathrm{Z}$ direction calculated for the two-pin configuration, respectively for a cooling time of 4,8 and $12 \mathrm{~s}$, are reported in figure 12a-c. The obtained 'saddle' shape of the deformed polymer disc is comparable to the observed deformation measured with the micro-CMM as reported in section 3.1 and figure 6. 

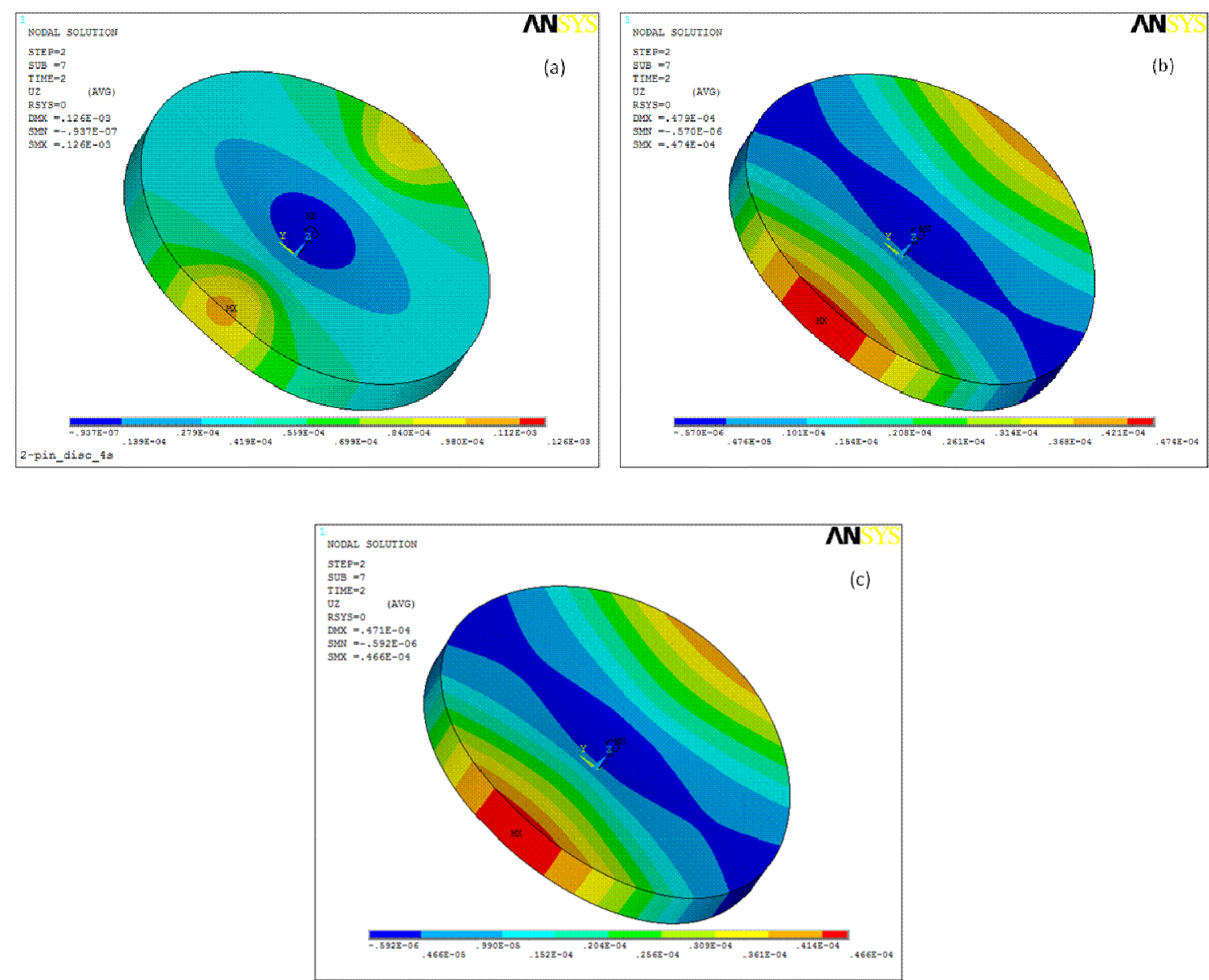

Figure 12. Displacement in $\mathrm{Z}$ direction for a cooling time of (a) 4, (b) 8 and (c) $12 \mathrm{~s}$

Further FE simulations have been conducted with a three and four-pin arrangement. The results of the calculated ejection warpage are reported in table 6 at different cooling times. Numerical results for the 2-pins configuration are comparable with the measured values (figure 6). The difference between the calculated and the measured ejection warpage could be due to combined estimation errors associated with the simulation method including: the meshing technique and the selection of the element type, the material properties, the friction forces calculation and the estimation of the friction coefficient, the temperature distribution of the PMMA within the mould.

Table 6. Calculated ejection warpage at different cooling times for the 2, 3 and 4-pins configurations

\begin{tabular}{l|ccc}
\hline \multirow{2}{*}{ Cooling time (s) } & \multicolumn{3}{|c}{ Ejection warpage $(\mu \mathrm{m})$} \\
\cline { 2 - 4 } & 2-pin & 3-pin & 4-pin \\
\hline 4 & 117 & 35 & 26 \\
12 & 44 & 5 & 4 \\
\hline
\end{tabular}


The results reported in table 6 show that a significant reduction in the ejection warpage can be achieved by modifying the ejection system by distributing the forces over a wider area. However, it is important to bear in mind that, in micro-moulding, increasing the number of ejection pins might not always be a viable option because of space constraints in the micromould.

\section{Conclusions}

This paper addresses the ejection warpage of micro-injection moulded miniaturised PMMA parts for application in microfluidic devices. The warpage on the miniature parts was measured using a microCMM. Aspects related to the micro-injection moulding process control, micro-mould manufacture and ejection system design configuration was addressed with the aim of reducing the warpage thus improving the parts flatness.

The micro-injection moulding process was optimized using a DOE approach on a two-pin configuration ejection system. A $15 \mu \mathrm{m}$ ejection warpage was achieved by selecting suitable process conditions. It was observed that the plastic deformation decreases with the increased cooling time. The trend can be explained by observing that for short cooling times, at ejection the core of the part is still at a temperature higher than $\mathrm{T}_{\mathrm{g}}$. Therefore the elastic modulus of the core material is considerably lower than the one of the skin layer. The longer the cooling time the lower the temperature averaged across the thickness and, therefore, the stiffer the part. This phenomenon is especially evident when the mould temperature is set close to $\mathrm{T}_{\mathrm{g}}$.

Diamond turning and micro-milling were both assessed as micro-mould manufacturing technique with the aim of controlling the ejection forces. The different roughness of the metal surfaces does not appear to significantly affect the part warpage.

The study on different ejection pin configurations suggests that a 3- or 4-pin ejection system would significantly reduce the warpage producing parts with flatness as low as $4 \mu \mathrm{m}$, which is actually the predicted process-induced flatness.

Future work will address the following points:

- Evaluation of the quality of new PMMA bonding techniques in relation to the polymer parts flatness

- Use of variothermal methods to minimize cooling time and to keep the mould temperature well below the polymer $\mathrm{Tg}$.

\section{Acknowledgments}

The authors would like to thank EPSRC for the Grand Challenge grant EP/C534212/1 to research "The design and manufacture of 3D-miniaturised integrated products" (“3D-Mintegration”).

\section{References}

[1] Attia U M, Marson S and Alcock J R 2009 Micro-injection moulding of polymer microfluidic devices, Microfluidics and Nanofluidics, 7 (1) 1

[2] Greener J and Wimberger-Friedl R 2006 Precision Injection Moulding: Overview and Scaling Considerations, in Precision Injection Moulding, Hanser Pulishers, Munich

[3] Attia U M, Alcock JR 2009 An evaluation of process-parameter and part-geometry effects on the quality of filling in micro-injection moulding, Mycrosyst. Tech., 15 (12) 1861-1872 
[4] Mönkkönen K, Hietala J, Pääkkönen P, Pääkkönen EJ, Kaikuranta T, Pakkanen T T and Jääskeläinen T 2002 Replication of sub-micron features using amorphous thermoplastics, Polym Eng Sci 42 1600-1608

[5] Ong N S, Koh Y H 2005 Experimental investigation into micro injection molding of plastic parts, Mater Manuf Process 20 245-253

[6] Aufiero R 2005 The effect of process conditions on part quality in microinjection molding, ANTEC: Proc Annual Technical Conf (Boston, MA, 1-5 May 2005) 36-40.

[7] Sha B, Dimov S, Griffiths C, Packianather MS 2007 Micro-injection moulding: factors affecting the achievable aspect ratios, Int J Adv Manuf Technol 33 147-156

[8] Tsao C and Voe D L 2009 Bonding of thermoplastic polymer microfluidics, Microfluid. Nanofluid. 6 1-16

[9] Shilpiekandula V, Burns D J, Rifai K, Youcef-Toumi K, Shiguang L, Reading I, Yoon S F 2006 Metrology of Microfluidic Devices: A Review, Proc. of International Conference on Micro Manufacturing ICOMM 49, University of Illinois, Urbana-Champaign, September 13-15

[10] You B H, Chen P, Park D S, Park S, et al., 2009 Passive micro-assembly of modular, hot embossed, polymer microfluidic devices using exact constraint design, J. Micromech. Microeng. 19 125025

[11] Goretty Alonso-Amigo M, Adams T 2003 Development of a plastic microfluidics chip: Early experimental results support the possibility of eventual mass production for clinical diagnostic applications, IVD Technology Magazine, March.

[12] Gale M T 1997 Replication techniques for diffractive optical elements, Microelectronic Engineering 34 321-339

[13] Kang S 2004 Replication Technology for Micro/Nano Optical Components, Jpn. J. Appl. Phys. $435706-5716$

[14] Hall H 2009 Polymer micro-optics: because size matters, Optics \& Laser Europe Magazine, May 2009

[15] Carr K, Ferreira P 1995 Verification of form tolerances Part I: Basic issues, flatness, and straightness Precision Engineering 17 131-143

[16] DD CEN ISO/TS 12781-1:2007, 2007 Geometrical product specifications (GPS) - Flatness Part 1: Vocabulary and parameters of flatness.

[17] Marson S, Attia U, Allen D M, Tipler P, Jin T, Hedge J, Alcock J R 2009 Reconfigurable Micro-mould for the Manufacture of Truly 3D Polymer Microfluidic Devices, Proc. CIRP Design Conference, 30-31 March 2009, Cranfield 343-346.

[18] Palm G, Dupaix R B, Castro J 2006 Large Strain Mechanical Behavior of Poly(methyl methacrylate) (PMMA) Near the GlassTransition Temperature, Journal of Engineering Materials and Technology 128 559-563.[19] Pouzada A S, Ferreira E C, Pontes A J 2006 Friction properties of moulding thermoplastics, Polymer Testing 25 1017-1023

[20] Bataineh O M, Klamecki B E 2005 Prediction of Local Part-Mold and Ejection Force in 
Injection Molding, Transactions of the ASME, Journal of Manufacturing Science and Engineering, $127598-604$

[21] Hamrock B J, Jacobson B O and Schmid S R 2000 Fundamentals of Machine Elements, McGraw-Hill, NY, Chap. 10 